\title{
GUERRA A LOS INTERESES EXCESIVOS
}

\author{
WAR ON EXCESSIVE INTERESTS
}

\section{Alberto LabBÉ VAlVERdE*}

La crisis actual es netamente financiera, no productiva, y su causa fundamental recae en la aceptación generalizada mundial de un cobro excesivo de intereses. Los intereses han pasado a ser una remuneración muy superior a la de cualquier actividad lícita del hombre, cuestión que la organización humana debe corregir de manera urgente.

En simple, podemos decir que interés es el lucro producido por el capital. Es el rendimiento o incremento pecuniario del capital. Corresponde al precio que tiene el dinero en el mercado financiero en un momento determinado.

Si bien es acertado que se haya dejado de lado la máxima de Aristóteles que sostiene que el dinero no engendra dinero, toda vez que es conveniente para el hombre el reconocimiento de que el préstamo con interés constituye un beneficio desde el punto de vista de la circulación de la riqueza, y por tanto para la sociedad en general, toda vez que el mutuante gana los intereses y el mutuario, gracias al mutuo, puede producir bienes, valores o servicios, no es acertado que en tal virtud, se permita el cobro de intereses excesivos.

En la antigua Roma, en el Digesto, se llamaba Usurae legitimae a los intereses equivalentes al uno por ciento mensual, es decir, doce por ciento anual, máximo permitido en la legislación anterior a Justiniano, el cual la rebajó al seis y al ocho para los comerciantes y al cuatro, para las personas de clase alta.

En la Edad Media el interés fue frecuentemente combatido por los teólogos, so-

\footnotetext{
* Abogado, Licenciado en Ciencias Jurídicas de la Pontificia Universidad Católica de Chile, Profesor auxiliar y Jefe del Departamento de Derecho Comercial de la Facultad de Derecho de la Pontificia Universidad Católica de Chile. Correo electrónico: alabbev@uc.cl
}

bre la base que el dinero era un bien que no producía utilidad, y por tanto era atentar contra la naturaleza la exigencia de intereses por préstamos en dinero.

Por su parte, la Convención Americana sobre Derechos Humanos, denominada "Pacto de San José de Costa Rica” suscrita por el Gobierno de Chile con fecha 22 de noviembre de 1969, aprobada por el Congreso Nacional con fecha 14 de agosto de 1990, ratificada con fecha 21 de agosto de 1990 y publicada en el Diario Oficial con fecha 5 de enero de 1991, señala en su Preámbulo entre otras consideraciones que: "Reiterando que, con arreglo a la Declaración Universal de los Derechos Humanos, solo puede realizarse el ideal del ser humano libre, exento del temor y de la miseria, si se crean condiciones que permitan a cada persona gozar de sus derechos económicos, sociales y culturales, tanto como de sus derechos civiles y políticos", y establece entre otros, el derecho a la igualdad ante la ley en su artículo 24, y agrega en su artículo $21 \mathrm{~N}^{\circ} 3$, a propósito de la consagración del derecho a la propiedad privada que: "Tanto la usura como cualquier otra forma de explotación del hombre por el hombre, deben ser prohibidas por la ley". En consecuencia, la autonomía de la voluntad en el Derecho Privado debe conciliar estos derechos esenciales, la libertad del hombre, su derecho a vivir en mundo libre, su derecho de propiedad (el cual no puede ser conculcado vía cobro de intereses abusivos como lo permite hoy la ley), y la igualdad ante la ley.

No obstante aquellos principios básicos del hombre en cuanto a la defensa de sus derechos fundamentales, en la actualidad el interés sobre el dinero ha pasado a ser por lejos mejor negocio que cualquier industria, actividad o trabajo remunerado lícito. De tal manera, se ha privilegiado en la economía y en la organización social del mundo actual la actividad finan- 
ciera por sobre las actividades productivas, extractivas, industriales, de servicios, en fin, de cualquier trabajo remunerado que no sea precisamente el vinculado al mundo financiero.

En Chile la Ley 18.010 sobre operaciones de crédito de dinero, otorga plena libertad a la estipulación de intereses, limitándola curiosamente, en relación solo al cobro que de ellos hagan las entidades financieras (Art. $6^{\circ}$ ), toda vez que dispone que los promedios de intereses máximos se establecen en relación con las operaciones efectuadas por las propias entidades financieras durante cada mes calendario.

Es decir, ello que en principio parece reconocer la plena libertad del mercado para determinarlas, no es efectivo, puesto que curiosamente solo reconoce la libertad del mercado financiero, dado que son tales entidades las que fijan sus intereses, ya que no es cierto que los negocien con su clientela, sino que a esta en la práctica general se los imponen, al menos a la clientela masiva o mayoritaria.

Esa anómala práctica de una libertad bien entendida pero mal aplicada, bien entendida porque parece apropiado que sea el mercado quién libremente determine el valor del dinero, ya que corresponde a sus dueños determinar si lo prestan o no y en caso positivo a que tasa, su mal aplicada práctica al aceptar que sean precisamente las entidades financieras, por lo demás ni siquiera dueñas del dinero qué prestan, quienes determinen el interés medio e incluso el máximo posible de cobrar legalmente, ello, ha precisamente permitido un mercado de intereses tremendamente injusto por el abuso de cobros excesivos principalmente de las entidades financieras y de las grandes tiendas.

Incluso, se permite aplicar, sin asombro al menos de ningún entendido en estas materias, intereses que simplemente no excedan en más de un $50 \%$ al corriente, denominándosele a este como "interés máximo convencional", siendo que en la práctica, como se ha indicado, casi nunca es convencional, ya que generalmente es impuesto por las entidades que los cobran.

Además, en virtud de la misma Ley citada, se permite cobrar intereses sobre intere- ses, capitalizándolos en cada vencimiento o renovación, esto último no inferiores a 30 días. $\left(\right.$ Art. $9^{\circ}$ ). Lo cual, que también en principio parece justo, produce enormes distorsiones en perjuicio del patrimonio de los deudores, los cuales constituyen las grandes mayorías de los pueblos de las sociedades organizadas. Solo se salvan aquellos pocos que no tienen necesidades de recurrir al crédito y aquellos muchos que ni siquiera tienen acceso a él.

Incluso en la actualidad el interés legal corresponde al interés corriente (Corte Suprema, Casación de Fondo Rol N 15.430 de 1991), conforme a la interpretación de carácter genérico que la jurisprudencia le ha dado a la norma respectiva (Art. 19 Ley 18.010), no obstante estar contenido en una ley especial.

Es cierto que la legislación común chilena contiene ciertas normas que parecen estar más en acuerdo con el planteamiento de este trabajo, en cuanto el Código Civil (Art. 2206) dispone que si el interés excede de una mitad al corriente, el juez deberá reducirlo a este último.

Pero ella no es bastante, toda vez que como se ha dicho, el interés corriente actualmente permitido, es desde ya abusivo por lo excesivo, poco razonable y atentatorio a los citados derechos básicos del hombre, lo que sin duda ha generado las grandes diferencias sociales de los últimos tiempos, y al ser ello de igual forma en el mundo, ha generado también la hambruna más salvaje, considerada en más de mil millones de personas (año 2009), sí, léase como se escribe, "personas" (solo piense si una de ellas fuera usted o uno de sus seres queridos, qué pensaría sobre lo planteado en estas líneas).

Lo anterior demuestra que la legislación chilena, que si bien acorde con el Derecho Internacional, legalmente hablando no permite el cobro de intereses por sobre los permitidos por la legislación, ni menos la usura, sí permite, al igual que el Derecho Internacional, el cobro excesivo de intereses, y por ende se ha legalizado y entronizado el abuso en esta materia, y de tal modo, la usura reina y se pasea por el mundo entero, ante la falta de conciencia de todos los que entienden de estas materias, en especial de aquellos pocos que lucran con ello. 
Por su parte, es cierto que la ley chilena contiene sanciones a la usura al disponer que comete el delito de usura (Art. 472 Código Penal) todo el que suministre valores de cualquier manera por un interés superior al máximo permitido estipular. Delito el cual tiene asignadas penas corporales, lo que demuestra la gravedad que la legislación otorga al abuso en materia de intereses, como concepto. Pero la abusiva aplicación de intereses aceptada por la propia ley, hace que la usura sea la utopía de un delito, ya que es casi imposible cobrar intereses de usura, si los propios intereses legalmente aceptados son en la práctica ya intereses usurarios.

Por su parte, en la práctica acaso ¡se ha sabido de muchos que hayan sido procesados o perseguidos por el delito de usura? Acaso, ¿no es usura el cobro de intereses cercanos al $50 \%$ o más de la deuda? E incluso, ¿no lo es el cobro de más de un $10 \%$ anual?

Todo ello pugna contra la buena fe, contra el amor, en fin, contra el propio hombre y contra la posibilidad de una vida pacífica en sociedad. Todo ello hace que no haya sido posible alcanzar el ideal del ser humano libre, exento de la miseria, y que no se hayan creado condiciones que permitan a cada persona gozar de sus derechos económicos, dado que tanto la usura como forma de explotación del hombre por el hombre, han sido y son permitidas por la ley.
El cobro excesivo de intereses constituye, si bien no una infracción a la ley porque ella erradamente lo permite, sí un enorme atropello a la moral en general y a los derechos del hombre.

Por su parte, es cierto que la organización actual del mundo financiero ha permitido enormes avances y también la generación de grandes fuentes de trabajo, sin embargo, no debemos olvidar que ello mismo ha perjudicado el desarrollo o el mantenimiento de muchas otras fuentes de trabajo, en particular de todos aquellos muchísimos que no han podido competir con la concentración cada vez mayor imperante en casi todas las actividades económicas. Por su parte, el hombre ha dejado de lado siquiera considerar que es de todos modos mejor vivir con menos y de manera que todos podamos tener al menos lo mínimo.

La definición a adoptar en esta materia es de la mayor relevancia a nivel mundial, y sin duda dependerá de si queremos que algunos se hagan ricos a costa del trabajo y sacrificio de todos, o bien, si queremos que se defina que pudiéndose realizar el negocio financiero, este en ningún caso pueda llegar a tener remuneraciones superiores a las que puedan esperarse de cualquier otro negocio lícito. En tal caso, los intereses solo podrían llegar en el mundo a ser razonablemente cercanos cuando mucho al $10 \%$ anual. 
